\title{
Open Streets or Taken for a Ride? Reforming Australia's Taxi Markets
}

\author{
Christopher C. Findlay and David K. Round
}

$\Gamma$ laxis have long been subject to regulation in Australian metropolitan areas by means of entry restrictions, quality and safety standards, and fare-setting procedures, ostensibly in order to protect the interests of taxi users. Entry is restricted by the obligation to own a licence; the monopoly rents attached to this regulation-induced scarcity have become capitalised in licence values. Such regulation is often inequitable, has restricted consumer choice, has reduced product diversity, and has sheltered the market from the dynamic forces of innovation and competition that promote efficiency. Yet governments have been reluctant even partly to deregulate the industry by issuing significant numbers of new taxi licences.

Regulatory barriers to entry and the absence of real substitutes at a comparable price have removed the incentive for taxi operators, whether individually or in the form of business organisations, to compete for business on any factor other than location. Jobs are apportioned by queuing at ranks and through use of the radio network. Apart from corporate accounts, little brand loyalty exists. Centralised setting of fares by taxi boards in all the major metropolitan markets has effectively removed price competition.

In recent years, however, several changes have forced taxi operators to re-assess their business strategies. Mobile phones have rendered drivers less reliant on radio networks. Hire cars have become more common, due to fewer regulatory restrictions, and have offered greater competition to regular taxis, such that some taxi operators now offer higher standards of comfort, cleanliness and driver courtesy. Talk of possible deregulation, formation of new breakaway cooperatives, and the emergence of niche operators offering specialised services have prompted existing drivers and firms to introduce new competitive strategies. Some people now own many taxi licences and employ large numbers of drivers. Yet individual independent owners have re-emerged, working entirely from mobile phones or from ranks, or in small informal networks. The industry is in a state of flux and uncertainty, especially as urban-transport options are being re-assessed by State governments, after proposals for regulatory reform by the Industry Commission (1994), and drawing

Christopher Findlay is Associate Professor of Economics at the University of Adelaide and an Associate of the Australia-Japan Research Centre at the Australian National University. David Round is Associate Professor of Economics at the University of Adelaide. 
on experience of regulatory reform in other countries, in particular New Zealand (New Zealand Ministry of Transport, 1991) and the US (Teal \& Berglund, 1987).

In our view, the potential for competitive behaviour is robust enough to justify substantial deregulation of the taxi industry. But whenever losers from a policy change can be identified, the question of compensation must be considered.

\section{Barriers to Entry}

All States control entry into the taxi market, by means of a licence system. In Sydney, Melbourne, Brisbane, Perth and the Northern Territory licence owners are required to be members of a radio network. Except in Brisbane and Melbourne, licence owners do not have to belong to an approved cooperative; and no State regulates the number of radio networks that can operate. All States stipulate maximum fares. In most cities the numbers of hire cars have also been controlled; in an attempt to confine them to a particular market and to differentiate them from taxis, they are often subject to other regulations relating to vehicle quality and age.

Licences (plates) have attracted prices in different cities in the ranges illustrated in Table 1. The price of a plate reflects the barriers to entry created by the licensing system. Such barriers reduce the total number of taxis and probably raise the average price of taxi fares above its free-market equivalent. When the demand for taxi services is strong and expected profits are high, the demand for plates is strong, and potential entrants into the industry have to bid higher prices for the right to enter. The rate of return on their investment is therefore reduced, given regulated fares, to one that is not much more than the rate of return on an investment of equivalent risk. This leads owners to press, through the regulatory system, for higher fares in order to provide a higher return on their investment in the plate.

\section{Table 1}

\section{Estimated plate values (A\$,000), 1988-93}

\begin{tabular}{rrrrrrrrr}
\multicolumn{2}{c}{ Sydney } & \multicolumn{2}{c}{ Melbourne } & \multicolumn{2}{c}{ Adelaide } & \multicolumn{2}{c}{ Brisbane } \\
Jan 1988 & 130.3 & Jan 1988 & 95.7 & Aug 1989 & 108.5 & 1989 & 153.0 \\
Jan 1989 & 179.6 & Jan 1989 & 134.9 & May 1990 & 80.0 & 1990 & 134.0 \\
Jan 1990 & 148.5 & Jan 1990 & 21.5 & Dec 1990 & 87.0 & 1991 & 137.5 \\
Jan 1991 & 148.5 & Jan 1991 & 117.6 & Jun 1991 & 88.0 & 1992 & 175.0 \\
Jan 1992 & 175.5 & Jan 1992 & 120.5 & Jan 1992 & 90.0 & 1993 & 190.0 \\
Jan 1993 & 198.0 & Jan 1993 & 133.0 & Feb 1993 & 117.0 & $1993^{*}$ & 125.0
\end{tabular}

*August

Source: State taxi industry associations and taxi boards. 
The barriers to entry do not confer riches on new owners, who pay all their expected profits to the previous owner of the plate. So the beneficiaries from regulation are those who bought plates at low prices and later sold them at higher prices. The Industry Commission (1994:393) has estimated that on average every taxi ride costs two dollars more than in the absence of restriction on entry.

Changes in plate values reflect the impact of a number of factors. Figure 1 shows the trends in plate values in Adelaide from 1974 to 1993. Prices dipped noticeably in 1990 as a result of government proposals to issue more plates to hire-car owners. The rising values suggest that the supply of plates has not kept pace with demand. Of course, many factors other than expectations about changes in the regulatory system affect the prices of plates, including driver costs, unemployment rates, redundancies in occupations with large pay-outs that increase the demand for plates, swings in demand for taxis, patterns of urban travel, and the costs of fuel and public transport.

\section{Figure 1}

Taxi plate prices in Adelaide $(\mathrm{A} \$, 000), 1974-93$

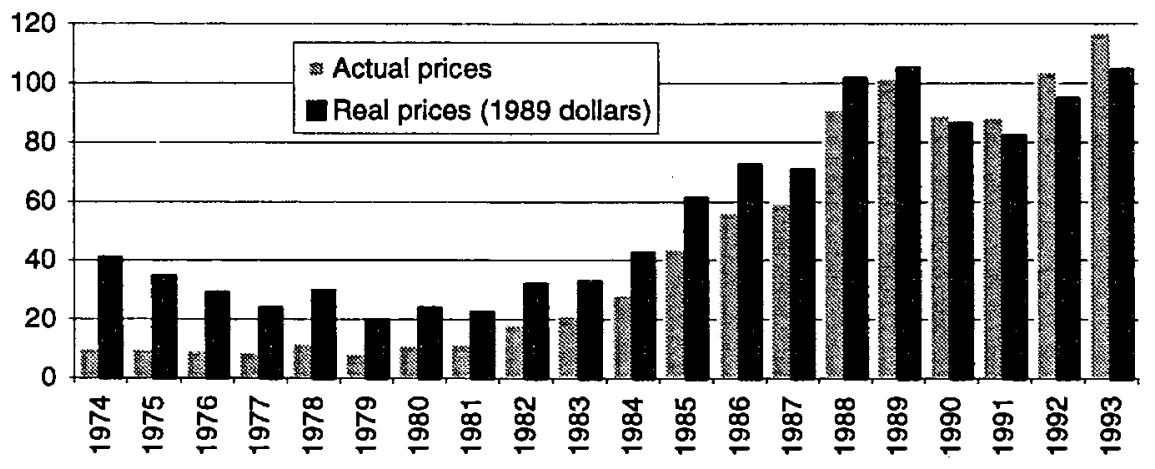

Note: 1993: two quarters only

Source: Private communication, SA Department of Transport.

Under a regulated market the operating licence constitutes a fixed cost that is not sunk so long as the market continues to be regulated and no new licences are issued (or at least so long as the number of new licences matches the rate of growth of demand). However, the licence immediately becomes an irretrievably large sunk cost if the industry is deregulated or if there is an imminent likelihood of deregulation. Such a loss in capital values is an important effect of deregulation. 


\section{The Impact of Technological Change}

A review of the number and size distribution of firms in major taxi markets indicates that in all cases the biggest operator has a large market share, and that those in Sydney and Melbourne enjoy a substantial advantage over their closest rivals (TPC, 1993). In all cities other than Sydney and Melbourne, the markets are supplied by four or fewer firms. This may reflect scale economies in the radio network that preclude the profitable existence of more, smaller, firms, or it may reflect the coordination difficulties of sharing radio networks once a certain critical number of taxis is reached. Yet the recent emergence of small taxi groups in some cities, operating through mobile phones, and the re-emergence of individual taxi owners also doing business on ranks and through mobile phones, indicate that changing technology will reduce the need for large cooperative radio facilities, though probably never to the point of irrelevance.

Estimates from various taxi industry groups suggest that between 10 per cent and 20 per cent of major metropolitan area cabs now carry either fixed or handheld phones, and that in most States this proportion is increasing. Of an estimated 600 Melbourne cabs with mobile phones, between 250 and 300 are believed to carry pagers so that personal overflow bookings can be handed off to other cabs rather than putting them through the radio network, possibly to be picked up by cabs offering lower standards than those expected by the passenger who called the original taxi. These developments, more than any other factor, have provided the impetus for the emerging segmentation in taxi markets, which is creating the background for better consumer service and choice and paving the way for the successful deregulation of taxi markets.

Some drivers, recognising that a demand exists for higher grades of service, have introduced innovations and offered special services to differentiate their taxis and secure repeat business. Some taxi firms have sought to differentiate some of their taxis by presenting them as 'Elite' taxis, which are generally newer vehicles with higher standards of presentation and uniformed drivers. Such taxis do not charge a fare premium for casual hirings. Most are fitted with mobile phones, and their drivers seek to establish passenger loyalty and secure repeat business by, for example, encouraging clients to make advance reservations. Elite-taxi owners have a strong incentive to win reputations for good service, since they can be summoned on demand by mobile phone. In contrast, little, if any, such incentive exists for taxi owners relying on the radio network, who cannot easily be allocated to passengers asking for them specifically. Mobile phones lead to cooperative radio networks spreading their fixed network costs over fewer jobs, though most drivers with mobile phones choose to remain associated with a radio network so as to be able to bid for jobs during times when they are not servicing their own clients.

However, a taxi driver cannot meet the demands from two or more customers simultaneously, unless some informal networking emerges with other operators who provide a service similar to that which a customer has received from the original driver. Network scale and scope economies, together with operational flexibility, 
could thus be developed by subsets of drivers who can certify that their services have desirable common characteristics.

\section{Market Failure in Deregulated Taxi Markets}

Although regulation of taxi markets has given rise to problems, there are many potential sources of failure in a free taxi market, although none of them is either inevitable or insoluble (Frankena \& Paulter, 1984). They raise issues about the abuse of market power and the quality of taxi services.

Waiting times too long. In an unregulated market, the number of taxis on the road could be smaller than is socially optimal. The more taxis there are on the road, the shorter the average waiting time is for all users. However, the individual taxi owner, in deciding to enter the market, will not take into account the benefits to all the users of the service that occur because of entry. As a result, the number of taxis could be too low relative to the socially optimal number. However, this is an argument for promoting entry into the market, not restricting it. Furthermore, current licensing and fare regulations provide drivers with little incentive to expand taxi services when demand is greatest, namely, at peak hours and in wet weather. If drivers could charge a premium at these times, they would be compensated for the opportunity cost of lost leisure time or for the extra strain of driving in inclement weather.

Service quality too low. Other aspects of service quality that have allegedly suffered in a deregulated market include the mechanical quality of taxis, driver skills, and the personal safety of travellers. Taxis offering high-quality services may not be able to charge correspondingly higher prices when consumers cannot distinguish their services at the time of purchase from those of the lower-quality taxis (as when they hail on the street or at a rank). If so, lower-quality taxis charging lower prices will tend to push higher-quality suppliers out of the market or into personalised-booking niche markets.

Yet the market might cope with these problems. New companies could emerge in order to act on behalf of consumers in monitoring the quality of the services their members offer. This service of brand identification and certification would reduce consumers' search costs and significantly lower their risk of making bad decisions. Such companies could identify themselves and their services by appropriately marking their cars.

The 'airport problem'. After deregulation, some consumers may hire taxis under disadvantageous conditions, such as late at night, at a fast moving queue at an airport or at a busy city rank. They may, as a result, suffer first-degree price discrimination.

However, if the problem is lack of information, or if taxi drivers can exercise monopoly power only in particular well-known locations, then a variety of solutions can be provided. For example, airport authorities or local tourist promotion authorities could offer advice to travellers or even offer the services of preferred taxi 
companies at prices that they negotiate on behalf of travellers (though this could involve cosy deals with particular taxi companies). Tourism authorities or hotels could offer specialised or contracted pick-up services for customers (with telephones available at the airport), or with taxi companies providing direct, free phone links to their control rooms.

The case is sometimes made for controlling taxi fares where taxi drivers have considerable short-run monopoly power. However, such controls may not be enforceable: the situation that creates the problem (immediate need for transport, lack of information and lack of current alternatives) will make it difficult to enforce the solution. As well, if maximum fares are set, fares will gravitate towards this maximum. Furthermore, setting maximum fares tends to discourage entrepreneurship. Taxi owners should be able to charge higher fares if they offer a higher quality of service, and should also be able to experiment with fare structures. An unregulated taxi market would provide a range of price and service options that are unlikely to develop under the dead hand of regulation.

\section{Regulatory Reform}

Safety and quality issues in the reform process can be dealt with, as the Industry Commission (1994:Section B4.3) suggests, by setting standards for vehicles and drivers. However, the mechanisms employed should not be used to create or entrench new monopoly rents.

Entry and safety considerations. Any operator whose vehicle meets stipulated safety and cleanliness standards, who carries adequate passenger insurance and who passes a comprehensive test of local geographic knowledge should be licensed to operate a taxi. However, certification would be necessary to ensure that minimum safety standards are met. To be effective, and to avoid capture by incumbents, certification would have to be carried out by bodies that are independent of the industry. The inspection scheme could be self-funding. To help ensure compliance with road-worthiness and insurance requirements, taxis could be subject to random inspection on the road.

Drivers must be licensed so that passengers can be confident that they are socially acceptable providers of public transport. In addition, taxi users would benefit if drivers could gain certification only if they can demonstrate a high standard of knowledge of the geography of the relevant metropolitan area. Examinations could be conducted by State motor-vehicles departments, which are already equipped to test applicants for a normal driver's licence, or possibly by State occupational licensing authorities, or through TAFE colleges, some of which offer courses in taxi driving.

These recommendations are aimed at protecting consumers from matters that might otherwise be beyond their control or knowledge. They do not constitute the re-emergence of regulation under a different guise, as the key competitive factors relating to taxi operation would still lie entirely with individual operators. Certification should be designed only to protect the public, not as a back-door method of 
controlling entry into a deregulated taxi industry. As it could be implemented through existing public and private infrastructure, its costs would be moderate, and could be recovered as charges on taxi operators. The impact of these charges on taxi fares should be minimal.

Avoidance of mechanisms for the creation or protection of monopoly rents. The substantial benefits of deregulation with respect to entry conditions and fare controls could be lost if monopoly controls remain or emerge in other key parts of the package after deregulation. Thus, it is essential that any new entrant into the market should have access to credit services and communications facilities, and that care be taken to ensure that new communications technologies cannot be captured by any one particular group such that it develops significant monopoly power in the market, or repressed by those with an interest in maintaining the pre-deregulation status quo.

In particular, in the short to medium term those who control radio networks must not be able to use their power as owners of a commercially essential facility to become de facto controllers of parts of the taxi market. If existing cooperatives were to exclude new entrants, taxi users who relied on phone bookings would be cheated of the benefits of competition. Equality of access to a radio network must therefore be guaranteed for all new entrants who can meet their fair share of the costs of running the facility. To achieve this, radio networks could operate independently of taxi cooperatives, although this could lose any benefits of integration and scope economies available through the joint provision of these two services. It is more important, however, that drivers who chose to remain members of existing radio networks should retain the commercial freedom to adopt additional new communications.

The traditional form of payment for taxi services has been cash, with some large users maintaining credit accounts. However, because of the advent of the Cabcharge credit system, to which most of the major taxi groups belong, cash fares from regular and corporate users of taxis services are now relatively uncommon. That Cabcharge is regarded almost as a universal currency among taxi drivers is clear from the emergence of a secondary market in Cabcharge vouchers. In this market, owners who do not belong to an officially accredited Cabcharge group accept Cabcharge vouchers, and then find acquaintances in the industry to cash them in for them, or sell them to other drivers at a discount, or exchange them for fuel or other vehicle services. In addition, some fleet owners who see cost advantages in remaining independent or having most of their cabs affiliated with a non-Cabchargeaccepting cooperative, affiliate one of their cabs to a Cabcharge-accepting group and through it submit for payment Cabcharge vouchers from all their cabs.

After deregulation, access to Cabcharge could be denied to new entrants, with a view to putting them at a competitive disadvantage vis-à-vis incumbent operators; and operators who wanted to offer credit systems in addition to Cabcharge could be threatened with the loss of their Cabcharge franchises. These possibility are made 
even stronger by the fact that Cabcharge is owned jointly by the major radio companies.

Fares. With taxi operators setting their own fares in a deregulated market, some supervisory mechanism would be necessary to ensure that taxis display prominently, both inside and outside, the current flagfall and distance charges.

Fares could increase after deregulation for taxis offering superior standards of comfort and accessibility, but with posted fares passengers could tell at a glance whether the cab's standards matched the posted price. A range of available prices, with drivers free to change them at will, and customers free to choose their desired price/service combinations, would be signs of competition at work.

It should not be expected, therefore, that in a deregulated taxi market all taxis would have the same fare structure. The range of prices would reflect varying degrees of product differentiation as the taxi market evolved into quality-based segments (for example, customers might be asked to pay more for an air-conditioned taxi). In addition, different drivers may have different goals, and different estimates of market demand conditions, so that posted flagfall and distance charges could vary between taxis, both at any given instant as well as from time to time as drivers respond individually to market forces of supply and demand.

\section{Compensating the Losers}

Should plate owners be compensated for the consequent fall in the value of their plates? Apart from the establishment of driver and vehicle certification procedures, compensation is the only significant hurdle standing in the way of immediate and total deregulation.

Governments might buy back plates after deregulation, in the interests of equity and fairness, but it would not be easy in practice to devise an equitable compensation scheme for current plate owners. In theory, this could be done if it could be shown that the gains from deregulation outweighed the losses in plate values. But in practice the mechanics of compensation are fraught with difficulties. A variety of mechanisms exists for compensating plate owners, each with different implications for the distribution of the capital loss. Compensation could be based on the original purchase price, as adjusted for inflation, the current market price, or some average of past values. The Industry Commission (1994:Table B4.1) estimates that the total value of plates in December 1993 was $\$ 2.5$ billion. Anything short of full market value compensation would be politically difficult; but the social opportunity cost of such payouts at a time of high budget deficits may render full compensation neither possible nor even socially desirable.

There are other difficulties. Should all plate holders be compensated equally? Should people who bought plates many years ago not be compensated, as they have enjoyed the opportunity to earn monopoly rents, whereas recent purchasers who have not been able to recoup their investments should be compensated more highly? But how should account be taken of the fact that there has been speculation for some time now that the taxi industry might be deregulated, and that the 
purchase price of plates in recent years might accordingly have reflected a discount to allow for that risk?

One possible solution is to tax the users of taxi services, but only for sufficient time to buy out existing plate holders at the lowest price thought to be politically feasible. A fund could be set up to buy out the existing plates, the fund being repaid by revenue from a tax on fares. The advantage of this proposal is the time limit placed on the burden borne by consumers. The disadvantage is that for some time taxi users will continue to carry the deadweight costs of regulation, thereby considerably negating the benefits of deregulation. A variation on this proposal would be an industry restructuring fund, financed by a levy on all annual taxi licences under a deregulated market, with existing licence holders able to apply to have their licences bought back. Applications could be dealt with by ballot or in some order of precedence (the rules for which would be controversial), with payments continuing until the fund is exhausted (Bitter, 1991:7). Under such a scheme, the industry pays for the buy-back of licences, although it is likely that the levy would be reflected, in a free market, to some extent in increased fares.

Other compensation possibilities were suggested by the Industry Commission (1994:Section B4.7). The industry could be gradually deregulated by selling new licences, equal to 5 per cent or so of the existing number of licences, say, every six months. Licence values would be reduced over time (although, depending inter alia on the rate of inflation, market demand for taxi services and the rate of increase of new licences, they might not change much in monetary value, even though the real value might fall), allowing the losses to be amortised by existing operators (Cousins \& McGinley, 1985:10). Sale proceeds could be redistributed to current licence owners.

Although deregulation of taxi markets would result in substantial net benefits to the users of taxi services in general, it is not necessarily true that all users would gain by the same amount, or that there would not be any losers. The current owners of plates would lose as the capital values of their licences virtually disappeared overnight. And if it is thought politically appropriate to subsidise these losses in some way, the payments would need to be financed either through general tax revenue, creating distortions and deadweight losses, or by a specific short-run user tax on users of taxis, forcing those who gain from deregulation to help provide compensation to licence holders for the capital losses that they will have incurred.

\section{Conclusion}

The seeds of deregulation have already been self-sown in the taxi industry. Innovative entrepreneurs have sought to lift themselves above their less progressive rivals by introducing new taxis, new services and greater levels of convenience and comfort for passengers, and by adopting new technologies. These operators stand to benefit most from deregulation.

Deregulation would significantly change the industry. Although the number of taxis on the road would almost certainly increase, especially in peak hours, New Zealand experience suggests that fares may not fall as much as might be anticipated. 
In addition, fares may cluster quite tightly around an industry 'norm' not because of collusion but because of the inherent forces at work in competitive markets. The market would probably still have for some time as its organisational focus the value of association with a radio network. This factor, together with access to Cabcharge credit facilities, holds the greatest potential for the maintenance of anti-competitive practices by incumbents as they try to forestall the competitive process in the taxi industry.

There is not likely to be a shortage of new entrants, as sunk costs are low; new providers of what might have been termed essential facilities could appear; and the competitive process would generate new ideas and mechanisms for providing information to consumers and for offering a range of services and prices. There is no case in a deregulated market for either an upper or a lower prescribed limit on fares. Upper limits inhibit entrepreneurial behaviour, resulting in less differentiation of taxi services than is socially optimal, and provide a benchmark below which taxi operators might not compete. Lower limits thwart the effective operation of the competitive process.

Consumers have suffered from taxi-market regulation in Australia. As communications technologies have developed, market forces have begun to assert themselves, offering consumers more choice and better taxi services. But until the barriers to free entry and independent behaviour by taxi operators are removed, and the streets opened up to competition, consumers will continue to be taken for a ride.

\section{References}

Bitter, C. (1991), The Taxi and Hine Vehicle Industry in Adelaide: A Futures Paper, Office of Regulation Review, Adelaide, June.

Cousins, D. \& L. McGinley (1985), Submission to the Taxi Inquiry-Melbourne and Metropolitan Area, Office of the Victorian Prices Commissioner, Melbourne, November.

Frankena, M. \& P. Paulter (1984), 'An Economic Analysis of Taxi Regulation', Bureau of Fconomics, Federal Trade Commission, Staff Report, May.

Industry Commission (1994), Urban Transport, AGPS, Melbourne (Report No. 37).

New Zealand Ministry of Transport (1991), Taxi Reforms - A Resource Kit, Land Transport Division, Wellington, June.

Teal, R. \& M. Berglund (1987), 'Impacts of Taxi Cab Deregulation in the USA', Journal of Transpart Economics and Policy 21: 52-4.

Trade Practices Commission (TPC) (1993), Submission to the Industry Commission Inquiry into Urban Transport, Canberra, December.

This article is a revised and edited version of contract research prepared by the authors for the Trade Practices Commission in 1993, which was used as the basis for the Commission's December 1993 submission to the Industry Commission's Urban Transport Inquiry. 